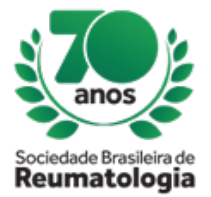

\title{
ANKYLOSING SPONDYLITIS, ANTI-TNF AND QUALITY OF LIFE
}

Adah Sophia Rodrigues Vieira (Universidade de Fortaleza, Fortaleza, CE, Brasil), Guilherme Lopes Pereira (Universidade de Fortaleza, Fortaleza, CE, Brasil), João Guilherme Farias de Sá Gomes (Universidade de Fortaleza, Fortaleza, CE, Brasil), Mariana Macedo Militão Mendonça (Universidade de Fortaleza, Fortaleza, CE, Brasil), Clarissa Oliveira Teles (Hospital Geral de Fortaleza, Fortaleza, CE, Brasil), Diego Germano Maia (Universidade de Fortaleza, Fortaleza, CE, Brasil), Rejane Maria Rodrigues de Abreu Vieira (Hospital Geral de Fortaleza, Universidade de Fortaleza e Universidade Estadual do Ceará, Fortaleza, CE, Brasil)

\section{BACKGROUND}

The United Nations defines the quality of life as an "expression used to verify the needs and living conditions of human beings", based mainly on the general well-being of the individual (physical, mental, psychological and emotional). In patients with Ankylosing Spondylitis (AS), several factors alter this wellbeing, such as chronic pain, deformities, and functional disability. Anti-TNF therapy, since its inception, has changed the natural history of this disease. The Ankylosing Spondylitis Quality of Life (ASQol) is a nationally validated, self-applicable, specific instrument to evaluate the quality of life of patients with ASs. It is composed of 18 questions focused on the influence of the disease on its daily routine, with the highest score indicating a worse quality of life.

\section{MATERIALS AND METHODS}

Cross-sectional and quantitative study, with completion of the ASQol questionnaire, in addition to demographic and anti-TNF therapy related data. The study was carried out at the AS outpatient clinic of a public hospital in the city of Fortaleza. It was approved by the Ethics and Research Committee, and the free and informed consent form was answered by the participants.

\section{RESULTS}

The study had a total of 104 participants, $74 \%$ male and $40 \%$ white. Sixty percent were under 45 years, and $68 \%$ had been diagnosed for more than six years. Smoking was seen in $9 \%$ and alcoholism in $21 \%$ of patients. Forty-three percent were professionally active, $27 \%$ were retired, and $30 \%$ were unemployed. Eighty-six percent of patients used anti-TNF. The average of the total ASQol scores was $14 \pm 5.03$. In patients using anti-TNF, the mean of the ASQol scores was 9. The ASQol score was significantly associated with the variables: education $(p=0.0001)$, exercise $(p=0.0055)$ and use of anti-TNF $(p=0.0095)$ (Table 1).

\section{CONCLUSION}

The ASQol is an easy-to-understand, self-applicable questionnaire to evaluate the quality of life of patients with ASs. The use of anti-TNF was associated with an improvement in the quality of life of the studied sample. 